\title{
On Therapy for Autistic Children Using Interactive Media Art
}

\author{
Ting Xu \\ $\mathrm{Ph}$. D. Student \\ Graduate School of Core Ethics and Frontier Sciences \\ Ritsumeikan University \\ Kyoto, Japan
}

\begin{abstract}
This paper is based on the theory of interactive media art. It refers to the understanding of various domestic and foreign scholars on interactive media art. It first indicates how interactive media art is different from traditional art and from its predecessor - new media art. Reflection on interactive media art suggests that it can help people in need and especially help break the self-enclosure of autistic children. There is some theoretical research on this question both in China and many other countries. There is nonetheless not much literature on the treatment of autistic children using interactive media art or on various methods of treating children with autism which explores the advantage and possible therapy for children with autism using interactive media art. In the previous studies, only a few existing interactive art cases and data consider the role of interactive media art in children's experiences, care and education. Through theoretical research, it will provide theoretical guidance for future research on autistic children in China.
\end{abstract}

Keywords: new media art, interactive media art, autistic children, experience, treatment

\section{Overview and purpose}

In the context of rapid development of modern media and Internet of things technology, the definition and popularization of interactive media art play a positive role in promoting the current human civilization and future development. Interactive media art combines art with science and technology. As a new subject of digital media art in the field of art design, interactive media art has broad prospects for development.

There are many names in China for digital media art in the academic world, but each has its own emphasis. Most are biased towards art, such as "multimedia network art" (Wan, Y., Wan, R., \& Chen,S.H., 2007), or "digital design art" (Chen, H.Q., \& Lv J.F., 2004), there is "interactive media art"1 (Guo, X. H., \& He, Y. J., 2008), as well as the opening of a program of information art design at Tsinghua University.

Different names are also used abroad, Myron Kruger (1983) put forward "artificial reality", Paul Milgram \& Fuio Kishino (1994) "mix reality", Stephen Wilson (2002) proposed "information art", Jay David Bolter and Diane Gromala (2003) "digital art", and David Robert \&Cynthia Breazeal (2010) "blended reality".

However, the above-mentioned approaches mostly focus on how these works are designed by computer, or in the case of art design on the principles of information processing. There is no comprehensive and thorough explanation from the perspective of art design, to help understand how to use it in life or in the market. In order to compensate that lack. In 2012, "interactive media art" was retained as the name of the discipline.

Interactive media art is an interlaced and interacting art form that uses various media. It is thus a new multi-media $\operatorname{art}^{2}$ centered on interactive ideas and interactive technologies. (Xu T., 2012). Bai \& Li (2007) write that "to interact" is defined in the "New Age English-Chinese Dictionary" and in the "Oxford English Dictionary" as a verb that refers to interaction, mutual influence, mutual restraint, and mutual induction.

\footnotetext{
${ }^{1}$ The "interactive media art" is different from "interactive media art"published by me in 2012. In my concept, the scope of media is broader and refers to the person or thing in which the two are related.

${ }^{2}$ The definition of new media art is narrow and broad.In a narrow sense, it is mainly an interactive and comprehensive art with "electronic" media and "optical" media as the basic language and digital technology as the core. Broadly speaking, the new media art is a form of artistic creation that is reflected in the use of traditional artistic expression techniques, along with the development of science and technology using new products. It is not a fixed term, it changes with the progress of science and technology and the development of society. (Chen Ling, 2007, p3)
} 
With the development of science and technology, and the wide use of electronic media and computers, to interact now also includes interactions between human and machine and between machine and machine (Bai, X. Z., \& Li, Y. N., 2007). There are further at least two different interpretations of the term "media". In the broad sense, as Marshall McLuhan (1964) pointed out, the term can be used to refer to any extension of the human body. In a narrow sense, "media" is a general term to refer to mass communication tools, such as the television, newspapers, radio, advertising and computer networks. In the interactive media art, media refers any communication tool, mostly electronic based but also traditional ones like a pen and paper.

Through the use of special materials and tools art reflects reality in various forms, but also sublimates from reality, it promotes a more social ideology that can resonate with many people, and applies aesthetic abilities and skills. Creative work can be full of passion and vitality, but art can also simply be a noun that refers to a collection in a museum. Traditional poetry, fiction, music, and dance are also art and understood as a verb, art is a process, for example a performance.

Interactive media art is different from traditional art forms. In a traditional art like music, listeners only listen. In traditional painting, the audience only looks at the painting.

Thus, in traditional art creation, the artist holds the monopoly of the art work, and the work is limited by the tools that convey the information. The audience can only to accept it. The work conveys information to the audience in a onedirectional way and does not need to obtain in return any information from the world in order to be completed. That limits most traditional works of art to being static. Of course, people are not simply blindly, passively watch. Different audiences have different aesthetic standards for judging art. However, audiences cannot feed their understanding back into the art works. That is, audiences cannot influence the art work with their own information (Chen L., 2007). In interactive media art the artist gives up his or her monopoly of power over the work and allows the 'experiencer' to respond actively. The art work itself interacts with the outside world. More people can participate in the work. The audience can participate in it, give feedback to the composer, and the artwork will change with the participation of the 'experiencers'. The transmission of information between the work and the experiencer becomes bi-directional. (ibid, 2007)

The work can pass information to the experiencer, and the experiencer can pass information back to the work. The work can be perfected by the participation of different experiencers. This cycle of information between the work and the experiencer is characteristics of interaction using different media. Although, as mentioned earlier, the media may include paper and other media such as metal or glass or a combination of both interactive media art mainly resorts to new media, which is to say those resting on electricity, using optical carrier, and requiring a computer or other electronic tools of artistic creation (Xu, 2015). Interactive media art is found in video art, in installation art, in game art, communication and network art, in interactive dance and interactive music, in virtual reality, and robotics. It thus encompasses a large variety of methods and tools and its defining characteristics is its interactive dimension.

In this paper, I want to consider the possibility of using interactive media art as a form of therapy for children with autism. Interactive media art is not only a frontier discipline in Chinese art design, it is not only part of the creative industry, but also needs to be people-oriented, to serve humanity. We need to apply theory to practice, and in turn to test whether this theory can help those in need.

Children with autism usually cannot communicate with each other or with other children. They live in the world by themselves, and even their self-perception is often limited. They need to be helped. I hope that with the help of interactive media art, exploiting its two way information transmission, its multi-sensory dimension and its fun aspects autistic children can come to learn through play and through different experiences. Thereby helping, educating and improving the life of these children.

The biggest difficulty which children with autism experience concerns communication. They seem to be closed upon themselves and some researchers see them as "mind blind", unable to recognize that others have a mind and one of their more obvious feature is lack of emotions (Baron-Cohen, 1995). One of the most distinctive features of the interactive art is the two-way dimension of information exchange it involves, so that information from the experiencer can be fed back to the work and further improve its design. It modifies the output.

Another remarkable feature of interactive media art is its multi-sensory integration. It does not only call upon visual experience, but mobilizes also a multi-sensory experience of touch, hearing and smell. This novel approach can help make these children interested, and perhaps learn some skills while playing.

\section{Children with autism}

\subsection{Concept}


Autism is a lifelong developmental disorder that occurs in a continuum called the Autism Spectrum Disorder (ASD).

The term was first proposed by Leo Kanner (1943) who described "early infant autism", which referred to behaviors such as obsessive-compulsive disorder, echolalia (repetition of words or phrases learned from others), and feelings of extreme isolation between the child and the world that surrounds him. Kanner believed that this condition had a genetic cause, because it is usually manifested in early infancy, and there often is a family history of obsessive-compulsive disorder. However, the view at the time was that bad parenting had a primary responsibility and autism was considered a mood disorder (Kanner, 1943; 218-221). Later, Hans Asperger (1944) wrote a paper presenting a behavioral pattern he called "autistic psychopathy". This is now called the Asperger Syndrome. He pointed out that children affected by this disease are difficult to integrate society, they lack non-verbal communication skills, and may be very clumsy with their peers. However, children with Asperger's Syndrome do not necessarily lack or delay language as do children with Kanner's autism (Asperger, 1944).

Today, ASD is described as a Pervasive Developmental Disorder (PDD) (Charman et al., 2003, 273), and it is more commonly understood by parents and professionals. It is now considered to have an organic basis. Yet, autism cannot be biologically tested and can only be diagnosed by examining the history and development of the individual and observing his or her behavior in various environments. The criteria used for diagnosis are achieved through consensus and redefined over time, illustrating the complexity of the state and trends of scientific thinking (Woolner, 2009, p17).

The symptoms of autism are broadly categorized as "a triad of impairments", which relate to (1) social interaction, (2) social communication, and (3) social imagination (The National Autistic Society (NAS)).Autism is characterized by widespread deficiencies in social interaction behavior, including language, joint attention and pragmatics (American Psychiatric Association,2000). This lack of communication is a very central topic of concern for researchers. Moreover, a common problem for children with autism is self-injury and aggressiveness. However, symptoms vary according to each individual child. Children with autism occur in a continuum of disorders, each child's symptoms are different.

In the " International Statistical Classification of Diseases and Related Health Problem 10th Revision",(ICD-10), the description of the obstacles to interactive social interactions for autistic children indicates that at least two of the following four items must be met: (1) inappropriate use of body language such as gaze, facial expressions, and posture adjusted to social interaction; (2) failure to develop and share peer relationships related to favorite things, activities, emotions, etc.; (3) lack of interaction of social emotions, and inappropriate response to other people's emotions, or failure to adjust behavior according to social situations, or to properly integrate social, emotional and communication behavior; (4) lack of sharing with others' or of sharing happiness with others (ICD-10, 2016. 22). In summary, whether it involves facial, linguistic, physical, emotional and other forms of expressions, the main issue is lack of interactivity.

I would like to consider the use of interactive media art, as a novel and interesting way to address these difficulties of children's social interaction, communication problems, and see if it can help them establish more intimate relationships with others.

\subsection{Previous studies of autistic children treatment}

In previous studies, research has mainly been carried out in the fields of medicine, including diagnosis and treatment, psychology, and psychiatry. There are also reports of attempts at treatments using music and art, as well as the use of modern technologies to treat children with autism, such as computers, virtual reality, and robotics. Among others, the Applied Behavior Analysis (ABA) approach relies on intensive, highly structured and repetitive lessons in which the child is rewarded for each correct response to a particular order. Interventions are usually performed at the pre-school stage. But recent research in Australia concluded that "the most effective interventions are interventions based on the child's ability or on the motivational nature of the activity, themselves rather than external rewards" (Puckett, et al. 2007).

Treatment and Education of Autistic and Communication handicapped Children (TEACCH) ${ }^{3}$ is tailored to communication tasks for individuals, starting with the evolution of communication methods, moving to more social aspects of communication. It is widely believed that most children with ASD benefit from structured educational methods and that they are visually motivated, so it is beneficial to apply visual methods to their lives and education (Woolner, 2009, p31).

\footnotetext{
${ }^{3} \mathrm{TEACCH}$ is a structured educational approach that promotes behavior through visual cues.
} 
In addition, in the 1980s there was an intensive interaction program at the Harperbury Hospital in the UK, originally known as the Augmented Mothering (Ephraim, 1986). It was designed to help individuals share their concerns with another person and develop more complex and ongoing communication relationships from there. This include activities such as eye contact and facial expressions, physical contact and gestures, and final vocalization. The key to these intensive interaction sessions is to coordinate people and people.

The therapists enter the individual's communication world, and although they may not initially understand it, they will participate in it to create meaningful interactions. Assuming that the individual's behavior begins to change gradually, new forms of communication can be developed and a way of attracting children away from their own inner world to other's external world can be created.

Similarly, in the United States, a project called Son-Rise became popular. The program trains parents to lead family interventions and assume some of the roles of therapists (Williams, 2006). This is a child-centred approach that teaches parents that their children are special and that their love and acceptance will enable them to follow and learn from them. Just like the intensive interaction method, Son-Rise teaches to replicate the child's behavior, and that learning from the children may form a route into their world.

In terms of music therapy, a study found that an autistic child with great social difficulties, after a few months of communicating with a music teacher, can follow the teacher's voice to develop the capacity to vary her voice to control the rhythm, melody and phrasing and even make her voice into a musical instrument for social interaction. Although the therapist emphasized that she did not learn to speak, this nonetheless shows that gaining music skills has the potential to help autistic children. (Neugebauer \& Lutz, 2005) In general the use of art to treat children with autism, art therapy, shows that art can help guide the development of autistic children, improve their ability to think, to create, and the development of stable emotions, as well as social adaptability (Zhang, 2009).

With the development of science and technology, researchers and therapists now are looking for new ways to help these children live, learn and experience. By using virtual reality, children can learn to simulate real life in a virtual world, such as crossing the road, communicating and other basic survival skills. In a virtual scene, we can assess whether children with autism have emotions, whether they can follow gaze, and their learning in the virtual world can be transferred to to real life (Parsons \& Cobb, 2011). I believe that interactive media art can also be used in this context. Especially considering that it can include visual, auditory, olfactory and other sensory experiences, and that it can generate interactions between people and things, people and people, things and things (Xu, 2012).

Similarly, wireless motion sensors can be connected to some real objects (balls, bags, chairs, etc.) and an avatar may asks the child to play the ball. In this case a sensor informs the system if the child fails, in which case the avatar corrects his/her movements (Konstantinidis et al., 2009).

There are other examples exploring how interactive media art can help autistic children, such as kaleidoscopes. Here the autistic children can interact with an interface to change patterns and thus discover the close relationship between patterns and various actions (Woolner, 2009). Singh et al., (2004) pointed out that in the snozelen multi-sensory interactive media art environment, compared to daily life (ADL) skill training and vocational training, autistic children's aggressiveness and self-jury are lower and this positive effect is later transferred to daily life. Therefore, resorting to this interactive multi-sensory environment has a positive impact on these children (Singh et al., 2004).

Some researchers have thus already explored the therapeutic effect of interactive art for autistic children. I would like to further consider how to conduct more in-depth research based on the theoretical background of interactive media art as well as inquiring more into the functions and advantages of interactive media art.

\section{The advantages of interactive media art: cases studies}

Interactive media art is, as mentioned earlier, a frontier discipline in art and design and the interaction between art and technology creates new possibilities. As we have just seen, there is some previous research on the treatment of children with autism. The reason why considering using interactive media art, to address the difficulties these children face is because these mainly consist in a social communication barrier and of behavioral repetitiveness while the essence of interactive media art is interactivity and creativity. Its interactive dimension offers advantages that distinguish it from other art forms that seem appropriate for this particular group of people.

Many researchers do not consider that robots, virtual reality, games, etc. may be part of interactive art but only view them as a robot, augmented reality, or games. However, the appearance of robots is the result of design, and they are made to interact. Games also have interactive and design elements. Further, there is an overlap between the behavior of gamers and that of experiencers of interactive media art in that they both participate to the performance and the content of the game/art work which is not just an exhibits but also also a common performance. 
Virtual reality is the focus of interaction between reality and the virtual, and its content is the embodiment of artistic design. Therefore, all of these can be viewed as interactive media art and can be relevant to therapy autistic children. Apart from its interactive and play dimensions interactive media art also has the advantages of increasing children's interest, providing a sense of relaxation; enhancing their capacity for joint attention ; and allowing for consensus building.

\subsection{Snoezelen case}

Snoezelen ${ }^{4}$ environment was first developed by a team in the Netherlands, and later applied in schools, after which it was copied by some organizations and commercial enterprises. It mainly addresses the needs of autistic children and provides a comfortable environment that enhances balance. The Snozelen project is a multi-sensory environment designed for people with autism, and especially also suffering from mental retardation, that provides multiple modes of stimulation; olfactory, through aromatherapy diffusers and assorted scents; vibrations and touches through vibrators and body massages; auditory, using electronic and natural sound generators; visual, with the use of laser light display equipment, interactive light panels with mirrors, interactive fiber optic fountains, fiber optic curtains, etc. In this environment, the child can, for example, touch a fiber strip, and the fiber strip gradually brightens as he or she touches it. Conversely, it can become darker. Different sounds can be produced by the child touching buttons. The child uses a "cable" as a brush that produces light which appears on a wall as with a a brush stroke.

Snozelen provides a low-sensitivity environment that can effectively reduce self-injury and aggression as shown by a 10 -week observation of aggressive and self-jury of adults with mental retardation and mental illness. This study using a one-way analysis of variance (ANOVA) ${ }^{5}$ of a comparison of professional and other skills training in the Snozelen space and in daily life activities (ADL) has shown significant differences. The effects of different treatment conditions on aggressive behavior, $\mathrm{F}(2,132)=15.01, \mathrm{p}<.01$. Aggressiveness under Snoezelen conditions was significantly lower than ADL skill training (mean difference $=2.42, \mathrm{p}<.01$ ) and vocational skill training (mean difference $=.93, \mathrm{p}<.05$ ). Significant differences were found in the effects of different treatment conditions on self-injury behavior, $\mathrm{F}(2.132)=$ $8.55, \mathrm{p}<.01$. Self-injury under Snoezelen conditions was significantly lower than during ADL skill training (mean difference $=10.42, \mathrm{p}<.01$ ) and was lower than during vocational skills training. A comparison of self-jury behaviors before and after the Snoezelen condition indicated a significant positive effect under Snoezelen conditions, $t(88)=2.03$, $\mathrm{p}<.05$. In the Snoezelen environment, individuals with mental retardation and mental illness exhibit less aggressive behavior and self-jury behavior than those under ADL or professional skills training (ibid, 2004, pp289, 290).

Snozelen provides a relaxing, safe environment that enhances the taste of the experience. It lets children learn while they play, gain knowledge and information. It is a new way of life for the children. There are not too many interference factors, the space is relatively relaxed, adults and children can participate in the experience, and the environment can be adjusted according to the needs of children. Finally, it is in agreement with what many therapists have said, that it is more important to give autistic children a relaxed environment than to interfere with them or even to provide treatment.

\subsection{Kaspar case}

Kaspar is a robot about the same size as a normal child. It is capable of subtle changes in expression which, combined with simple gestures, effectively conveys information about specific emotions. The robot is operated remotely via a wireless remote control, and through its movement the robot interacts with the child. When the children say they are bored, the experiment stops.

\footnotetext{
${ }^{4}$ Sozelen was developed in the Netherlands in the 1970s and has been established in institutions around the world and is particularly common in Germany which has more than 1,200 of them. It is a method to treat autism and other developmental disorders, such as dementia or brain damage. It includes placing people in a soothing and stimulating environment called the "Snoezelen Room." These rooms are specifically designed to provide a variety of sensory stimuli, using lighting effects, colors, sounds, music, smells and more.

${ }^{5}$ Analysis of variance (ANOVA) is a common statistical model in data analysis, mainly to explore continuous data type.
} 
The robot is used as part of an interactive environment that promotes and encourages social skills for children with autism.

For example, Kelly is a six-year-old girl with severe autism, who secluded herself from others and even her mother cannot easily communicate with her. Kaspar was introduced to her in an experiment. Kelly expressed she wanted to approach the robot, then after she explored Kaspar for a while, and began interacting with Kaspar, paying close attention to its face, especially its eyes, and even trying to imitate the robot playing the tambourine. In addition, Kelly stretched out her hand reaching for the experimenter's hand.

Kaspar provides an excellent experience for body involvement - especially with touch, interaction of gaze following. Kaspar creates an environment that makes touch and gaze become relevant and possible. Through his or her interaction with Kaspar, over time the child gains the same ability to interact through touch and gaze with the therapists.

Another example is that of Leroy a severely autistic child. When Kaspar was introduced to him, Leroy showed great interest in the robot. He often explored the surface of the robot and he was interested in Kaspar's eyes and eyelids. Interestingly, in later stages, he began to touch and explore his own eyes, as well as explore his teacher's eyes and face. Finally, after playing with Kaspar for a few weeks every week, Leroy began sharing his excitement with his teacher.

Andy is a 16-year-old autistic teenager with attention deficit and only able to pay attention for a short period of time. He can be aggressive to others and may inflict self-injury. When he was introduced to Kaspar, he was very relaxed and interested in Kaspar and very gentle. As soon as he was allowed, he focused on Kaspar, exploring Kaspar's facial features closely and then exploring his own facial expressions. Throughout the experiment period of 12 weeks his attitude and interest in Kaspar remained strong. Although Andy refused to sit next to Kaspar with another child, and ignored the therapist's request only using the remote control to interact with the robot, he gradually accepted a simple imitation interaction with the therapist, watched and learned from the therapist how to imitate Kaspar.

Leroy and Andy have shown a sense of other people, or rather, they pay attention to certain characteristics of Kaspar's behavior. Kaspar is likely to be understood by them as paying attention to other people who are co-present. Therefore, Kaspar facilitates the possibility for them of sharing emotional responses and seeing the behavior of co-present other people as relevant to the simulated interactions (Robins,B., Dautenhahn, K., \& Dickerson, P., 2009). Thus, by interacting with Kaspar, children increase their social awareness and capacity for joint attention.

The robot also provides a safe interactive environment for children, especially those with autism. Interactivity enhances fun and relaxation, but in an interaction between two children if one child hits another he/she may be hit in return and may even be injured. In interaction with the robot or other interactive art environment, this will not happen. The child can control and manipulate this object, but because the robot remains physically unaffected and cannot be hurt and therefore hurt back, the child can experience his or her feelings, relax, and gain information or knowledge in a safe and relaxed environment.

\subsection{TRPG an interactive tabletop game}

The Tabletop Role Playing Game (TRPG) is a standard role-playing game. The emergence of Dungeons \& Dragons (D\&D) has made such games popular. TRPGs generally require 3-5 persons to participate. One of them is the Game Master (GM), who is called the underground city master in the war chess TRPG such as "D\&D", in "Dark World" he or she is called the "Storyteller" (ST), and is called game host in a TRPG such as Generalized System (GURPS). The Game Master is responsible for explaining the plot and explaining the role of non-player character (NPC), such as villagers, monsters, etc.; he or she also records time and makes decisions on the player's behavior. Others players are those who play the various roles of the game. The process of playing the game is called "running the group."

In this TRPG game, the GM is the author or staff, and the playersare 23 ASD diagnosed children 5 Asperger, 8 highfunctioning autism, and 7Pervasive Developmental Disability (PDD) , 3Pervasive Developmental Disorder (Not Otherwise Specified). They are playing the roles of warrior and magician. Through communication, use the recording paper, dice, writing tools, etc. they play the game according toset rules.

They are divided in groups of 3-6 people, a total of 5 groups, each group a total of 5 sessions, once a month, the spontaneous conversation with the partner.

Here, the communication between players is itself an interaction, and everyone participates in this interaction. In this it is similar to interactive art, which unlike traditional art requires participants to change from passive viewing to active participation, experience.

Through the exchanges that take place during the game and the voicing of multiple opinions, positive changes in ASD children's spontaneous behavior are promoted, and through the interactive game, the become able to build consensus. (Kato, 2017). 


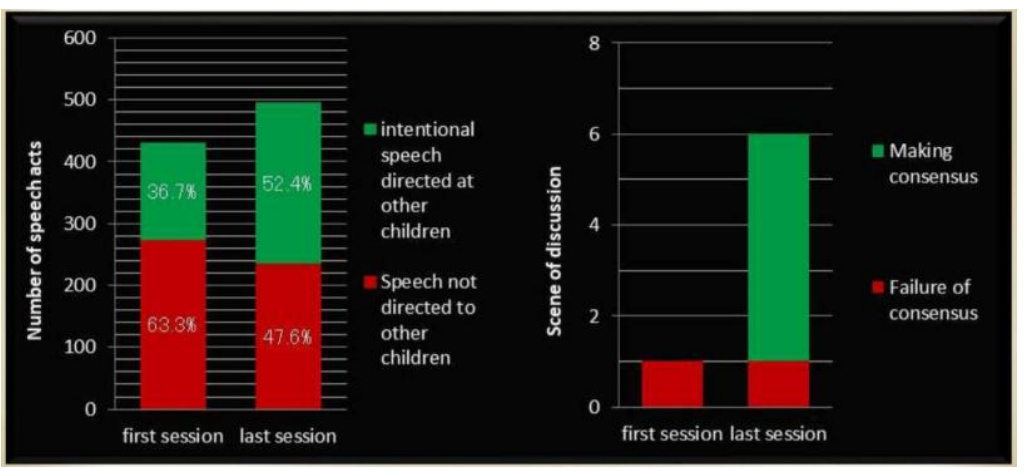

Research on promotion of interpersonal negotiation of children with autism spectrum disorder: Support of conversation by table talk role playing game (TRPG), Kato, 2017

Questionnaires before and after TRPG activities were conducted for the ASD children participating, and the quality of life scores (QOL) of participating children were reported to have increased significantly (Kato, 2017).

Furthermore the questionnaires' results show that through interactive games, promote the cultivation of the voice of autistic children and make them build consensus. Not only do children develop communication skills, but TRPG playing also enhanced their self-confidence. It proved beneficial for their life, their ability to learn, to get along with friends and to study at school.

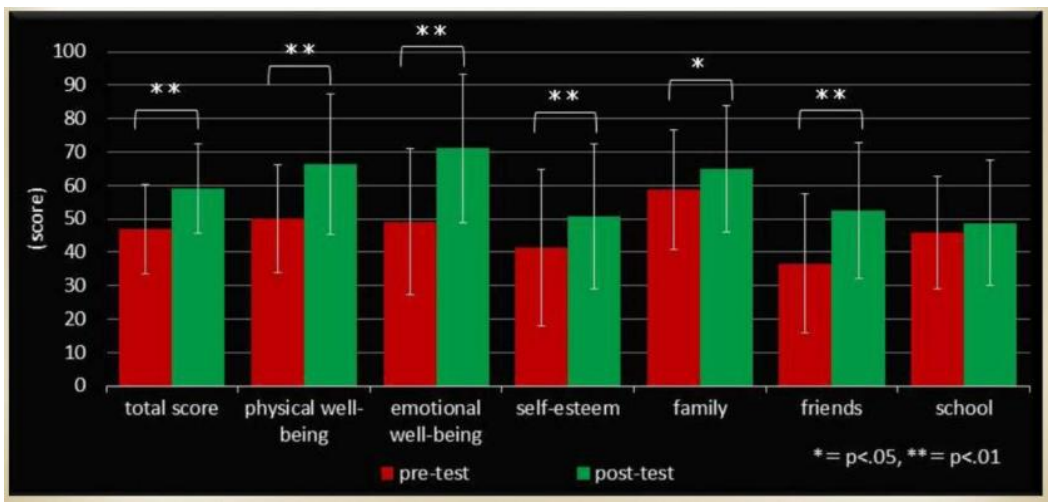

Research on promotion of interpersonal negotiation of children with autism spectrum disorder: Support of conversation by table talk role playing game (TRPG), Kato, 2017

\section{Conclusion}

In this paper, I mainly discussed three examples. These three examples have been chosen because they reflect different dimensions or similarities of interactive media art forms, and have different advantages for autistic children, increasing children's interest, providing a sense of relaxation; enhancing their capacity for joint attention; and allowing for consensus building.

The Snozelen case indicates it can provide a relaxed environment for children, further one thatcan be adjusted according to children's needs. As many therapists have said, it is more important to provide a relaxed environment for autistic children than to interfere with them and even provide treatment.

The Kaspar case shows that the autistic children's interest in Kaspar are strong. That the robot is explored leading toeye and body touches and this discovery of the body facilitates the possibility for them of sharing emotional responses and seeing the behavior of co-present other people as relevant to the simulated interactions.

The TRPG interactive game case shows that the type of interaction it provides, enables children with autism to build a consensus and consciously speak. Not only do children develop communication skills, but playing the game also enhances their self-confidence. This is beneficial to their quality of life, their ability to learn, to get along with friends and to study at school.

Autism occurs in a continuum called the autism spectrum disorder. For different types of symptoms, there needs to be different ways to address the difficulties of different children, and interactive art can provide this difference. It can be a work of art or product, or it can be a display space that autistic children can explore. 
Program adjustments are made according to the needs of different children. On the basis of traditional media art, interactive art can consider a variety of media, especially through computers, sensors and other electronic devices, incorporating interactive elements. Interactive art can also be used as an artistic performance, but the interaction of the artistic performance with the work or the environment, will give feedback to the experiencers, such that in a sense the robots, or interactive environment, become "live". They can be controlled, manipulated, but this feedback does not affect the child physically, causing physical hurt to the children, that is, children can truly feel the experience in a safe and relaxing environment to learn, gain information and knowledge.

In the future, I would like to explore the use of cutting-edge professional interactive media art theory in the context of China's situation to experiment with autistic children, and further consider the feasibility of a more in-depth study.

\section{References}

American Psychiatric Association. (2000). Diagnostic and statistical manual of mental disorders (4th ed.). Washington, DC.

Asperger, H. (1944). Die schizoiden Psychopathien im Kindesalter.Archiv für Psychiatrie und Nervenkrankheiten. 60 (3-4): 248-261. Retrieved April, 11th, 2019 from: https://doi:10.1159/000316609

Bai, X. Z. ,\& Li, Y. N.(2007) . Innovative Thinking of Interactive Art. Beijing: China Light Industry Press. 4. (白雪竹, 李颜妮. (2007).互动艺术创新思维. 北京 : 中国轻工业出版社.)

Baron-Cohen, S. (1995). Mindblindness: An Essay on Autism and Theory of Mind.Cambridge,Massachusetts: MIT Press.

Bolter, J.D. \& Gromala, D. (2003). Windows and Mirrors: Interaction Design, Digital Art and the Myth of Transparency.Cambridge,Massachusetts: MIT Press.

Chen L. (2007).New Media Art History: A journey towards integration. Beijing: Tsinghua University Press. 3, 146, 112.(陈玲.(2007).新媒体艺术史纲:走向整合的旅程.北京: 清华大学出版社)

Chen, H. Q. \& Lv, J. F. (2004）.Digital Design Art.Beijing:People's Fine Arts Publishing House. (陈汗青,吕杰锋. (2004). 数码设计艺术. 北京：人民美术出版社)

Dautenhahn, K., \& Werry I. (2004). Towards interactive robots in autism therapy Background, motivation and challenges, Pragmatics \& Cognition, 12(1), 1-35.

Ephraim, G. (1986). A brief introduction to augmented mothering. Playtrack pamphlet, Harpebury Hospital School, Radlet Herts.

Guo, X. H., \& He, Y. J.(2008).Interactive Media art. Chongqing: Southwest Normal University Press. (郭晓寒，何雨 津.(2018). 互动媒体艺术. 重庆 : 西南师范大学出版社.)

International Statistical Classification of Diseases and Related Health Problem 10th 9 Revision. (2016). ICD-10. 22.

Kanner, L. (1943). Autistic Disturbances of Affective Contact, The Nervous Child. 2: 217-50.

KatoKohei..(2017).

Research on promotion of interpersonal negotiation of children with autism spectrum disorder: Support of conversation by table talk role playing game (TRPG). Ph.D. thesis,

Tokyo Gakugei University, Japan. Retrieved April, 11th, 2019 from http://hdl.handle.net/2309/147692(加藤, 浩 平.(2017).自閉スペクトラム症児の対人相互交渉の促進に関する研究: テーブルトーク・ロールプレ イングゲーム (TRPG) による会話の支援)

Konstantinidis, E. I., Luneski, A., Frantzidis, C. A., Costas, P., \&Bamidis, P. D. (2009). A Proposed Framework of an Interactive Semi-Virtual Environment for Enhanced Education of Children with Autism Spectrum Disorders, In: Computer- Based Medical Systems, CBMS 2009. 22nd IEEE International Symposium on.1-6.

Kruger, M. (1983) . Artificial Reality. Addison-Wesley. ISBN 0-201-04765-9

Lewy, A. L., \& Dawson G. (1992). Social stimulation and joint attention in young autistic children, Journal of Abnormal Child Psychology, 20 (6), 555-566.

Marshall McLuhan. (1994).Understanding Media: The Extensions of Man. Cambridge,Massachusetts: MIT Press. 17.

National Autistic Society. [Online] Retrieved April, 11th, 2019 from: https://www.autism.org.uk/

Neugebauer, Lutz. (2005) .The importance of music therapy for encouraging latent potential in developmentally challenged children, In Music Therapy Today, a quarterly journal of studies in music and music therapy , 4, 656-677. 
Parsons, S., \& Mitchell, P. (2002) .The potential of virtual reality in social skills training for people with autistic spectrum disorders, Journal of Intellectual Disability Research, volume 46 part 5, 430-443. ま

Puckett, K., Mathur, S.R. , \& Roxanne Zamora. (2017) Implementing an Intervention in Special Education to Promote Social Skills in an Inclusive Setting. Journal of International Special Needs Education, 20(1), 25-36. Retrieved April, 11th, 2019 from: https://doi.org/10.9782/2159-4341-20.1.25

Robert, D. \& Breazeal, C. (2012).Blended Reality Characters. HRI'12 Proceedings of the seventh annual ACM/IEEE international conference on Human-Robot Interaction.359-366 https://doi:10.1145/2157689.2157810

Robins, B. \& Dautenhahn. K. \& Dickerson.P.(2009). From Isolation to Communication: A Case Study Evaluation of Robot Assisted Play for Children with Autism with a Minimally Expressive Humanoid Robot.Second International Conferences on Advances in Computer-Human Interactions. Mexio.

Singh, N. N. , Lancioni, G. E. , Winton, A. S., Molina, E. J., Sage, M., Brown, S., \&Groenewe, J.,et al./ (2004) . Effects of Snoezelen room, Activities of Daily Living skills training, and Vocational skills training on aggression and self-injury by adults with mental retardation and mental illness, Research in Developmental Disabilities. 25. 285-293.pp289, 290.

Utsumi, A., Milgram, P., Takemura, H., \& Kishino F.(1994). Investigation of Errors in Perception of Stereoscopically Presented Virtual Object Locations in Real Display Space. Proceeding of the Human Factors and Ergonomics Society Annual Meeting. Retrieved April 28,2019fromhttps://doi.org/10.1177/154193129403800413

Wan,Y., W, R., Chen,S.H. (2007). Multimedia Network Art, Chongqing:Southwest Normal University Press. (万延, 万 蓉,陈少华.(2007). 多媒体网络艺术.重庆:西南师范大学出版社).

Williams, K. R.(2006). Intervention for autism: Prerequisites for evaluation. National Autistic Society. Retrieved April 9,2019from https://doi.org/10.1177/1362361306062012

Wilson, S. (2002) . Information Arts: Intersections of Art, Science, and Technology. Cambridge,Massachusetts: MIT Press.

Woolner, A.(2009). Using interactive digital media to engage children on the autistic spectrum, A thesis submitted in partial fulfillment of the University's requirements for the Degree of Doctor of Philosophy. Available: Retrieved February 2011 from http://curve.coventry.ac.uk/open 17, 30, 31.

Xu, T. (2012). Interactive Media Art.Shenyang: Fine Arts Publishing House, 2012.2, 44.(许婷. (2012). 互动媒介艺术. 沈阳：辽宁美术出版社)

Xu, T. (2015). Media Art Appreciation, Tsinghua University Press, 10,12, 124, 261.（许婷. (2015). 媒介艺术欣赏. 北 京:清华大学出版社.)

Ziegler, J. C., Stone, G. O., \&Jacobs, A. M.(1997).What is the pronunciation for-ough and the spelling for /u/?Behavior Research Methods, Instruments, \& Computers,29(4), 600-618.

Zhang, W. (2009). Multi-factor investigation and analysis of autistic children and intervention in painting art therapy. Retrieved February13, 2019 from

Http://xueshu.baidu.com/usercenter/paper/show?paperid=eb13d2565caef8001690f150f38ed207\&site=xueshu_se 